\title{
PLASTIC POLLUTION: CAUSES, EFFECTS AND PREVENTIONS
}

\author{
Obebe S.B., Adamu A.A. \\ Department of Mechanical Engineering, \\ Bayero University Kano, \\ P.M.B. 3011, Kano, Nigeria
}

\begin{abstract}
Most of today's plastics are made from Organic polymers produced from petroleumbased Chemicals. This may change as scientists shift to developing plastics made from biologically based chemicals. With the production outspacing almost every other material production, plastic waste is now one of the biggest environmental scourges of the time. The scale of the challenge is daunting. The exposure of humans to plastic pollution also has health challenges. According to the state of plastics report, only nine percent $(9 \%)$ of the nine billion tonnes of plastic in the world ever produced has been recycled. Most ends up in landfills, dumps or in the environment especially the oceans. The research methodology used is based on the interactions with the plastics industries, the Environmentalists, Medical Practitioners, Ministry of Environment, Ministry of Health, and Bottling Companies. This paper is also based on visits to restaurants, and events centres, examination of nooks, crannies, and drainages.
\end{abstract}

Keywords -Landfills, Environment, Discard, Debris, Degradation, Biodegradable, Plastic, Recycling, Environmental Effects, Health Effects,

\section{INTRODUCTION}

Plastic pollution is the accumulation of plastic particles and objects in the Earth's environment that adversely affect humans, wildlife and wildlife habitat [1]. Pollutants are substances that adversely affect the health, activities or survival of a population [2]. Every day, thousands of tons of pollutants are discarded into the air by natural events and human actions. Far more damaging are the substances discharged into the atmosphere by human actions [3]. Plastics acting as pollutants can be classified based on their sizes into three aspects which are: micro debris plastic, mega debris plastic, and micro debris plastic. According to [1], mega plastics and micro plastics have accumulated in highest densities in the Northern Hemisphere, which is concentrated around the current carrying the debris, plastic can be found off the coast of some islands. Mega-plastics and micro-plastics are normally used in the manufacturing of packaging materials (such as plastic bottles, plastic bags etc.), footwear and other domestic items. These are later found being washed off of ships or discarded in landfills. Some of the items used in fishing activities are also found around remote islands. All these are still known as microplastic, meso-plastic and macro -plastic.

Plastics are in expensive and durable. These are the reason why the plastic production by humans are very high and the demand keeps on increasing day by day. Human activities have the potential to endanger human life and the natural ecosystems. This is experienced when plastics such as plastic bottle, plastic bags etc are being utilised/used for packaging, after they are being utilised, it is realised that they are discarded recklessly without thinking of what will be the consequence. These plastic wastes litters everywhere when not well discarded/disposed affecting the wildlife, wildlife habitat, humans and producing chocking, and pungent odour. Therefore, plastic pollution can affect land, waterways and oceans. The figure 1 below shows plastic pollution afflicting land.

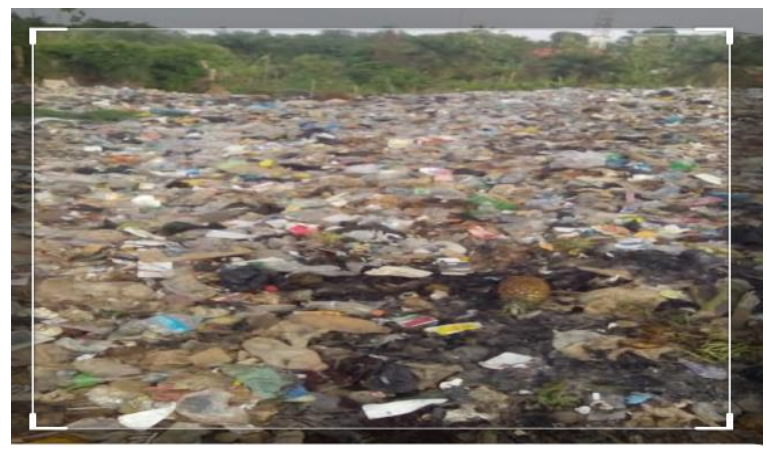

Fig.1. Shows Plastic Pollution Afflicting Land. 


\section{International Journal of Engineering Applied Sciences and Technology, 2020 \\ Vol. 4, Issue 12, ISSN No. 2455-2143, Pages 85-95 \\ Published Online April 2020 in IJEAST (http://www.ijeast.com)}

Source: wasteaid.org

Most plastics have chemical structure which makes them to be highly resistant to many natural processes of degradation and as a result of this it takes them a long period of time to degrade. These two factors have resulted into enormous presence of plastic pollution in the environment and at the same time affecting human health adversely. As the human population grows exponentially, so do the demands for plastic increases without thinking about the consequences after being used/utilised when discarded/disposed. This population continue to grow as the amount of garbage produced by people increases. These disposable products such as bottles of water, soda cans, plastic bag etc are discarded/disposed easily, but the accumulation of these products have resulted to increase in the amounts of plastics pollution around the world.

\section{LITERATURE REVIEW}

Plastic debris is classified as either primary or secondary. Primary plastics are in the state of their original form when collected. Examples of these are cigarette butts, microbeads, and bottle caps. Secondary plastics, on the other hand, are referring to smaller plastics that are obtained as a result of degradation of primary plastics.

The search for biological based plastics dates from 1913 when a French Scientist and a Brutish Scientist filed independently for patents on a soy-based plastic. At that time, there was intense competition between the petrochemical and agricultural industries to dominate the market for plastics made from organic polymers. Henry Ford, who developed the first Ford motorcar, supported research on the development of a bioplastic made from soybeans. A 1914 photograph showed him using an ax to strike the body of a car made from soy bioplastic to demonstrate its strength. But as oil became rudely available, petrochemical plastics took over the market. Now with projected climate change and other environmental problems associated with the use of oil, chemists are stepping up efforts to make biodegradable and more environmentally sustainable plastics from a variety of green polymers. Such bioplastic can be made from corn, soybeans, sugarcane, switchgrass, chicken feathers, and some components of garbage. Also the $\mathrm{CO}_{2}$ extracted from coal-burning power plant emissions could be used in this process. The key to making such biopolymers is to find chemicals, called catalyst, which will accelerate reaction that chemists can use to form polymers from biologically based chemicals without having to use high temperatures. With proper decision and mass production, such bioplastics, could be lighter, stronger and cheaper, and the process of making them could require less energy and produce less pollution per unit of weight than is involved in the making of conventional petroleum-based plastics. Instead of being sent to landfills, packaging made from such bioplastic could be composted to produce a soil conditioner, in keeping with the nutrient recycling principle of sustainability. Presently, Toyota is investing 38 billion dollar in a process that makes plastics from plants. By 2020, it expects to control two-thirds of the world's supply of such bioplastics [4].

According to [2], billions of metric tons of solid wastes are dumped, burned, and buried annually in the United States alone. This includes 50 billion non-returnable cans and bottles. Paper products make up one-half of the total volume of solid wastes. In natural ecosystems, solid wastes are recycled but we humans bury them in landfills or incinerate them. Incinerators can add heavy metals and other pollutants to the air and leave a highly toxic ash that must be disposed off safely. Land that is both available and acceptable for landfills is scare and becoming scarer. All landfills eventually "leak", posing a threat to groundwater supplies. That is one reason why communities increasingly take the "Not In My Back Yard" (NIMBY) approach to landfills. On the plus side, more and more people now participate in recycling programs. In addition to recycling, you can play a role by refusing to buy goods that are lavishly boxed and wrapped, packaged in indestructible containers, or designed for one-time use.

According [1], estimation shows that 1.1 8.8 million metric tons (MT) of plastic waste gets into the ocean from the surrounding coastal communities each year. Living organisms, especially seal marine animals become harmed either by mechanical effects such as problems related to ingestion of plastic waste, entanglement in plastic objects, or through exposure to chemicals with the plastics that interfere with their physiology. Among the effects on humans include the disruption of various hormonal mechanisms causing hormonal disorder. As at the year 2012, there was an estimation that there is approximately 165 million tons of plastic pollution in the world's oceans. Research shows that China, Indonesia, Philippines, Thailand and Vietnam dump more plastic in the sea than all other countries in the world. A study gave estimation that there are 


\section{International Journal of Engineering Applied Sciences and Technology, 2020 \\ Vol. 4, Issue 12, ISSN No. 2455-2143, Pages 85-95 \\ Published Online April 2020 in IJEAST (http://www.ijeast.com)}

more than 5 trillion plastic pieces of different sizes such as microplastics, large microplastics, mesoplastics and microplastics floating on the sea. The litter being discharged into the oceans is toxic to marine life and humans. The toxins that made up the components of plastic include diethyhexyl phthalate, which is a toxic carcinogen, as well as cadmium, mercury and lead. As at the year 2018, there was availability of about 380 million tons of plastic being produced worldwide each year. From the 1950s up to 2018 , there was an estimate of 6.3 billion tons of plastic which has been produced worldwide, of which an estimated 9\% has been recycled and another 12\% has been incinerated.

According to [5] , he predicted that if the current consumption patterns and waste management practices continue, by 2050 , there would be around 12 billion tones of plastic litter in landfills and the environment. By this time, if the growth in plastic production continues at its current rate, them the plastic industry may account for 20 percent of the world `s total oil consumption. The growing trend has given nightmare to environmentalists and sanitation agencies in Nigeria. Plastics litter all nooks and crannies of major cities and towns. The most common are plastic drinking bottles, food wrappers, plastic grocery bags, plastics bottle caps, straws and stirrers, plastic lids, other types of plastic bags, and foam take-away containers. Like in advanced countries, Nigerians have been caught up with a throwaway culture that treats plastic as a disposable material rather than a valuable resource to be harnessed. No day passes without commuters throwing plastic bottles on the streets. The indiscipline has reached a feverish level. Everywhere you go, empty plastics litter the surroundings and becoming a nuisance. Most plastics do not biodegrade. Instead, they slowly break down into smaller fragments known as micro plastics. Therefore, there have been important efforts to reduce/alleviate the prominence of of free range plastic pollution by reducing plastic consumption, promoting plastic recycling, and litter cleanup.

According to [6], Cameroon, among the other courtiers in the world, plastic, placed a ban on non-biodegradable plastic shopping due to the adverse effects it has on the environment. These plastic bags have made the roads and streets untidy and clog seas and rivers. It has become a serious threat to wildlife. These plastic bags are made using energy and non-renewable resources such as oil which are unfriendly to the environment.

\section{CAUSES OF PLASTIC POLLUTION}

The plastics causing the pollution are in different sizes from big to microscopic. There are many kinds of plastics. They exist depending on their precursors and method for their polymerization. The main contributory factors to the problem of plastic pollution are fishing nets, plain old trash, disposing of plastic and garbage, and over-utilisation of plastics.

- Fishing Nets: Fishing is an agricultural activity normally practised all over the world. The commercial aspect of fishing is an economic necessity in which people consume fish for their daily survival and maintenance of good balanced diet. The ocean has faced different problems of plastics pollution created by the fishing industry. The nets used for large scale fishing activities are usually made of plastic. At the initial stage, these fishing nets become submerged in water, on spending much time it releases toxin at will. Later, they get broken up. This kills and harms the local wildlife, but it ensures that pollutants enter the water and fish of the area. According to [1], most ocean plastic pollution comes from Chinese cargo ships as said by the ocean cleanup spokesperson. The largest ocean-based source of plastic pollution is discarded fishing gear which includes traps and nets, and it is estimated to be up to $90 \%$ of plastic debris in some areas. Continental plastic litter gets into the ocean largely through storm-water runoff, flowing into watercourses or directly discharged into the coastal waters. Plastic in the ocean has been shown to follow ocean currents which eventually form what is known as Great Garbage Patches. The knowledge of the routes that plastic follows in ocean currents comes from the accidental container drops from ship carriers. For example, in May 1990, the Hansa carrier, sailing from Korea to the United States, broke apart due to a storm, which resulted into thousands of dumped shoes and these eventually started showing up on the U.S. Western coast, and Hawaii. The estimate show that over 400,000 marine mammals perish every year due to plastic pollution in oceans. Marine organisms become caught in discarded/disposed fishing equipment, e.g. ghost nets. The ropes and nets used for fishing activities are often made of synthetic materials such as nylon, which makes fishing equipment more durable and buoyant. These organisms can also become caught in circular 


\section{International Journal of Engineering Applied Sciences and Technology, 2020 \\ Vol. 4, Issue 12, ISSN No. 2455-2143, Pages 85-95 \\ Published Online April 2020 in IJEAST (http://www.ijeast.com)}

plastic packaging materials, and if the animals continue to grow in size, the plastic can cut into their flash. Equipment such as nets can also drag along the seabed there by causing damage to coral reefs [1].

- Plain Old Trash: Plastics are found everywhere along the streets and roads of every cities and towns in Nigeria making them to be untidy. The cartons of some products such as can-milk, canbeverages, can-tomatoes are lined with plastics so as to allow proper packaging. Plastic drinking bottles, water bottles, straws and stirrers used for soft drinks in hotels, restaurants and events centres for entertainment during conferences, seminars, symposiums, wedding receptions, Annual General Meetings (AGMs) etc are disposed/discarded littering everywhere by the participants and invited guests ignoring the environmental consequence. Some of these products may even contain tiny plastic beads. Whenever one of these items is being discarded/disposed or washed down a sink, the toxic pollutants pose threats to the environment there by causing harm. Trash dumps and landfills are major problems because the pollutants are allowed to get into the ground thereby affecting the wildlife and groundwater. According to [1], the plastic pollution on the land poses a threat to the plants and animals including humans occupying the land. The estimates of the amount of plastic concentration on land are between four and twenty three times that of the ocean. The amount of plastic poised on the land is greater and more concentrated than that in the water.

- Disposing of Plastic and Garbage: Plastics have complex chemical composition. This makes plastic to be durable and do not break down easily. Plastics and resins have different properties related to contaminant absorption and adsorption depending on their chemical composition. The polymer degradation takes a long period of time due to saline environments and cooling effect of the sea. These are contributory factors to the persistence of plastic debris in certain environments. Findings carried out by the marine experts have made them to predict the rates of decomposition of different plastic products. It is estimated that a plastic beverage holder will take 400 years, a foam plastic cup will take 50 years, a disposable nappy will take 450 years, and fishing line will take 600 years, to degrade. The burning of plastic is toxic which can harm the atmospheric conditions resulting to deadly illness. Therefore, if it is in a landfill, the releasing of toxins in that area is continuous. Most of the wastes in the form of plastic in landfills, are single-use items such as packaging. When plastics are being discarded /disposed in this way, it leads to accumulation. But, disposing plastic wastes in landfills has less of a gas emission risk than disposal through incineration, the landfills has space limitations. Another factor to be considered is that the liners acting as protective layers between the landfills and environment can break, thereby leaking toxin and contaminating the nearby soil and water. The recycling of plastics is not enough to reduce the large number of plastics that litters everywhere. The process of recycling plastic could result to the release of plastic irritants and harmful chemicals into the environment.

- Over-utilisation of Plastics: This refers to plastics being over-used. It is less expensive and durable. These enable both the priviledged and less priviledged people in the society to afford patronising plastic materials/items. It is one of the most widely available and over - used item in the world today. When plastic is disposed/ discarded, it does not decompose easily there by polluting the land or air nearby when burnt in the open air. Also, plastic items that are not properly discarded can be carried to oceans through storm waters.

\section{ENVIRONMENTAL EFFECTS OF PLASTIC POLLUTION}

Plastics consist of major toxic pollutants having the potential to cause important harm to the environment in the form of water, land and air pollution. Plastic is a material that is nonbiodegradable, hence it can wreak havoc on natural environment resulting into long-term issues for animals, plants and humans. The distribution of plastic debris varies due to some factors among which are wind and ocean currents, urban areas, coastline geography, and trade routes. The population of humans in some areas also plays a large role in this. Plastic are normally found in enclosed regions such as nooks and crannies of cities and towns thereby affecting the environment. This plays the role of distribution of organisms to remote coasts that are not their natural environments. Among the effects plastic pollution has on our environments are groundwater pollution, upsetting of the food chain, killings of animals, land pollution, poisonous ability, air pollution, expensiveness.

- Groundwater Pollution: Groundwater is water that is present in rocks or unconsolidated 


\section{International Journal of Engineering Applied Sciences and Technology, 2020 Vol. 4, Issue 12, ISSN No. 2455-2143, Pages 85-95 \\ Published Online April 2020 in IJEAST (http://www.ijeast.com)}

materials below the Earth's surface. Groundwater forges a link between surface water systems and the material in Earth's Crust [7]. According to [8], groundwater in its natural state tends to be relatively free of contaminant in most areas. Because it is a widely used source of drinking water, the contamination of groundwater can be a very serious problem. Our drinking water, whether we buy it in bottles or get it out of the tap, originally comes from streams and lakes on Earth's surface or from groundwater [7]. This shows that the world's water is in great danger due to the leaking of plastics and waste. When rain falls, all these garbage dumps, landfills, and plastic wastes that litters everywhere become leached into the groundwater supplies which is part of our drinking water. Groundwater and reservoirs are susceptible to leaking environmental toxins thereby resulting into contaminated water. Plastics have littered and polluted the world's ocean having adverse effects on it. This has caused devastating environmental consequences on many marine species thereby creating adverse effects on the people consuming fish and other marine life for their nutrients.

- It Upsets the Food Chain: A food chain is a linear sequence of who eats whom in an ecosystem. Most species belong to more than one food chain, especially when they are at a low feeding level [2]. An ecosystem consists of one or more communities of organisms interacting with one another and with the physical environment though a flow of energy and a cycling of materials [2]. According to [2], each species in an ecosystem has its own position in a hierarchy of feeding levels/tropic levels. A key factor in how any ecosystem functions is the transfer of energy from one of its feeding level to another [2]. The food chain consists of producers, consumers and decomposers. Most of the organism in the food chain feeds on the plastic wastes. The plastic wastes come in different sizes be it large or small. Due to this, the tiniest organism in the world such as plankton is being. affected by plastic pollution. When these organisms, being producers, feed on plastics, they become ingested and poisoned, thereby causing problem for the higher animals, being consumers, that depend on them for food in the food chain. This leads to obstruction in the food chain and ecosystem as whole. Also, this can cause a lot of ingestion of highly toxic carcinogens and chemicals in plankton, fish, and mainly the humans, through the food chain.
- Killings of Animals: The availability of plastic wastes such as plastic bags and containers, sixring plastic can holders etc in the crannies and nooks of the environment that are being discarded each day has resulted in the death of some animals such as duck, dolphins, fish, fowl, turkey, tortoises etc in the environment when they become trapped in them or poisoned from the toxins released by plastics wastes. This causes adverse effects to the surrounding animals thereby affecting the ecosystem. According to [1], many marine organisms such as fish, turtles, birds etc have become entangled in plastic debris which is responsible for their deaths. These animals become caught along the way in the debris and end up suffocating or drowning. Due to their inability to untangle themselves, they also die from starvation or from their inability to escape predators. Being entangled also often results in severe lacerations and ulcers. It was estimated that at least 267 different animal species have suffered from entanglement and ingestion of plastic debris in the 2006 report known as plastic debris in the World's Oceans. [5] said that the economic damage caused by plastic waste is vast. Studies reveal that the total economic damage to the world 's marine ecosystem amounts to at least 3 billion dollar yearly. It has also impact on the tourism, fishing and shipping industries.

- Land pollution: Plastic waste are normally dumped in landfills. When this takes place, there is interaction with water there by forming hazardous chemicals. When these chemicals seep underground, the quality of water become degraded. Wind has contributed to plastic pollution thereby carrying and depositing plastic from one place to another, increasing the land litter. The plastic wastes can also get stuck on trees, fences, towers, poles, traffic lights, roofs etc and the animals coming in contact with them in the surrounding and might suffocate them leading to death. According to [9], the supply of open land and a free- enterprise system of waste collection and disposal led most American communities to opt for dumping urban refuse in landfills. In earlier periods, most of these were simply open dumps on the land, a menace to public health and esthetic blot on the landscape. Beginning in the 1960s, more stringent Federal controls began to require waste disposal in what was considered a more environmentally sound manner called the sanitary landfill. This involves depositing refuse in a natural depression or excavated trench, compacting it, and then 


\section{International Journal of Engineering Applied Sciences and Technology, 2020 \\ Vol. 4, Issue 12, ISSN No. 2455-2143, Pages 85-95 \\ Published Online April 2020 in IJEAST (http://www.ijeast.com)}

covering it each day with soil to seal it. Open dumping was outlawed in 1976. Some $75 \%$ of the country's municipal waste is disposed of by landfill. In the 1970s and 1980s, there was a real fear that the available, affordable, or permitted landfill sites were rapidly disappearing the cost of solid waste disposal would soon greatly increase. Some two - thirds of all landfills in operation in the late 1970s were failed and closed by 1990, and more than half the cities on the East Coast were without any local landfill sites in the middle 1990s. Because of changes in garbage economics during the 1990s, however, those earlier fears proved unnecessary.

Plastic pollution on land poses a great threat to the plants and animals including humans who inhabit the land and making them not comfortable with the environment. Mismanaged plastic wastes ranges from sixty (60) percent in East Asia and Pacific to one (1) percent in North America. The percentage mismanaged plastic waste reaching the ocean annually and thereby becoming plastic marine debris is between one third and one half the total mismanaged wastes for that year. Chlorinated plastic can release harmful chemicals into the surrounding soil, which can then seeps into groundwater or other surrounding water sources and also the ecosystem of the world. This can result to serious harm to the species that drink the water [1]. As the toxic chemicals released from plastic wastes on interaction with water seeps into the soil, it makes the soil to be infertile and affects the plant growth. The landfills located near oceans often contribute to ocean debris because the content is easily swept up and transported to the sea by wind or small waterways like rivers and streams. Marine debris can also result from sewage water that has not been efficiently treated, which is eventually transported to the ocean through rivers.

- Poisonous Ability: The plastic pollution is poisonous. Plastic pollution has the potential to poison animals, which can then adversely affect human food supplies. A number of toxic chemicals are artificially used by man to produce plastic. Generally, the use of and exposure to plastics has been linked to numerous health concerns which is affecting people all over the world. The plastic pollution is highly detrimental to large marine mammals. It poses single greatest threat to them. Some marine species, such as sea turtles, have been found to contain large proportions of plastics in their stomach. When this occurs, the animal because starved. This is because the plastic blocks the digestic tract of the animal. Sometimes, marine mammals become entangled in plastic products such as nets, which can harm or kill them. The processes of producing, storing, using, disposing of, and just being around plastics can be totally dangerous/detrimental to living things. Toxins from emissions, fly ash, and slag in a burn pile can travel long distances and deposit in soil and water, eventually entering human bodies after being accumulated in the tissues of animals and plants.

- Air Pollution: It is the presence of chemicals in the atmosphere in concentrations high enough to harm organisms, ecosystem, or human made materials, or to alter climate [4]. Today, air pollution is a global problem; areas far from the polluting source may be adversely affected as at atmospheric, circulation moves pollutants freely without regard to political boundaries [3]. When plastics are burnt in the open air, landfills or incinerators, poisonous/toxic chemicals are released thereby causing environmental pollution. Also, discarded plastics contribute to Greenhouse gas emission to the atmosphere having adverse effects on both humans and animals when inhaled. Therefore, the polluted air when inhaled by animals and humans affect their health thereby causing endocrine and respiratory problems etc.

- Expensiveness: Plastic pollution is expensive. As landfills and incinerators are common everywhere, it costs millions of Nairas/Dollars every year to clean up the affected areas after being exposed. This has led to the loss of life to animals, plants, and humans inhaling toxical chemicals from plastic wastes. The land becomes more valuable as it is being used for different purposes and to find a place to put garbage and trash has become a problem in many parts of the world. Excess pollution results into decrease in tourism and recreational centres in the affected areas thereby affecting the economy.

\section{HEALTH EFFECTS OF PLASTIC POLLUTION}

Plastic pollution occur when plastic accumulates/gathers in an area and begins to have negative impact on the natural environment thereby creating problem for plants, wildlife, and the human population. This involves killing plant life, and posing dangers to humans and local animals. Plastics is an incredibly useful material both at home and 


\section{International Journal of Engineering Applied Sciences and Technology, 2020 \\ Vol. 4, Issue 12, ISSN No. 2455-2143, Pages 85-95 \\ Published Online April 2020 in IJEAST (http://www.ijeast.com)}

larger societies, and it is made from toxic chemical compounds which can cause illness in humans.

According to [1], the study carried out in 2017 showed that $83 \%$ of tap water samples taken around the world contained plastic pollutants. This was the first study to focus on global drinking water pollution with plastics, and showed that with a contamination rate of $94 \%$,tap water in the United States was the most polluted, followed by Lebanon and India. European countries such as the United Kingdom, Germany and France had the lowest contamination rate, through still as high as $72 \%$. This means that people may be ingesting between 3,000 and 4,000 microparticles of plastic from tap water per year. The analysis found particles of more than 2.5 microns in size, which is 2500 times bigger than a nanometer. Currently, it is not clear if this contamination is affecting human health, but if the water is also found to contain non-particle pollutants, there could be adverse effects on human well-being, according to scientists associated with the study.

Plastic is known to disrupting hormonal growth and carcinogens. The chemicals that are used in the production of the main feedstocks for plastics have some known human health impacts/effects which include neurological, cancer, reproductive, and developmental toxicity, impairment of the immune system, birth defects etc. research showed that the human health impacts/effects of plastic production have made us to know that complex, important, intersecting and dangerous human health impacts/effects occur at every stages of the plastic lifecycle which ranges from wellhead to refinery, from store shelves to human bodies, and from waste management to the current impacts as water, air, and soil pollution. It is unhygienic for human body to be exposed to the toxins released from plastics. In the manufacturing of plastics, the health concerns/issues is of great consideration which has much focus on additives (such as bisphenol A (BPA) and a class of chemicals called phthalates) that go into plastics during the manufacturing process, which make them to be more flexible, durable, and transparent. The utilisation of plastic products normally leads to inhalation and/or ingestion of large amount of both microplastic particles and hundreds of toxic substances with known or suspected developmental, carcinogenic, or endocrine disrupting impacts/effects. The use of plastic can also be connected with public hygiene and prevention of bacterial contamination. For instance, the people in Taiwan, normally use plastic straws to drink everything in liquid form from beer to milk out of fear of a contaminated supply chain. Therefore, consumers need to be very careful/cautious of chemicals leaching into food or drink products. It is advisable for humans to keep away from PVC (often found in pipes) and PS (Styrofoam, often used as food/drink containers).

Most plastics originate from crude oil. It is only the plastic labeled PLA that are made from the sugars in corn or other plant such as cassava etc. research showed that $99 \%$ of plastics come from fossil fuels. The extraction of oil and gas, especially hydraulic fracturing for natural gas, releases an array of toxic substances into the air and water, often in large volumes. These toxins have direct and documented impact/effects on eyes, skin, and other sensory organs, the nervous, respiratory, and gastrointestinal systems, brain, and liver of humans. When converting fossil fuel into plastic resins and additives, carcinogenic and other highly toxic substances are releases into the air. The effects of exposure to these substances include reproductive and developmental problem, impairment of the nervous system, leukemia, cancer, and genetic impacts such as low birth weight. The industry workers and communities that are neighours to refining facilities are at a greatest risk and face both chronic and acute exposures during uncontrolled releases and emergencies.

In the environment, the microplastics enter the body of humans through direct exposures resulting into ingestion or inhalation which can lead to an array of health impacts/effects which include oxidative stress, inflammation, genotoxicity, apoptosis, necrosis, dizziness and unconsciousness, which are linked to an array of negative health outcomes which include cancer, cardiovascular diseases, diabetes, chronic inflammation, inflammatory bowel disease, rheumatoid arthritis, auto- immune conditions, neuro-degenerative diseases, and stroke.

\section{PREVENTION OF PLASTIC POLLUTION}

The rate at which plastic waste grows in the world today is discouraging and uncalled for. A global plastic wastes disaster is being faced by people which is suffocating our environment and causing damage to the ecosystems. These ecosystems need to be protected from future damage and actions need to be taken to establish a world with free-plastic wastes. The industrialists are in possession of the ability to change the various ways the world utilises/uses and wastes plastic. So, the ecosystems, wildlife and 


\section{International Journal of Engineering Applied Sciences and Technology, 2020 \\ Vol. 4, Issue 12, ISSN No. 2455-2143, Pages 85-95 \\ Published Online April 2020 in IJEAST (http://www.ijeast.com)}

oceans need to be restored to a healthy state and change the world into one with no plastic waste. Some of the measures reducing plastic wastes are:

- Reuse: Reusability refers to the use of materials more than once in their original form instead of throwing away after each use. This does not only ensure the maximum use of the material life span but also reduces waste. Reuse has increasingly been accepted as playing a vital part in addressing a wide range of social challenges related to poverty, health and well-being. It should be made known to the public that, reuse is not specifically a waste issue. It is an opportunity for goods to have a second life. Never the less, to some extent, it allowed reduction in the amount of non-biodegradable plastic bags used [6]. Plastic items can be reused or used for different purposes such as the bottled soft drinks after use, instead of 8 throwing it away, it is used to bottle the processed product of maize, guinea corn, millet etc in Nigeria and other parts of the world. Poor management of the plastic can cause pollution, although it has some advantages also. It is important for humans to put into consideration how plastic can be reused. People should bring their own reusable shopping and produce bags to markets, and avoid using single use plastic bags. Use a shopping bag and do not use the available plastic bags. Findings showed that many companies are presently selling reusable water bottles as a substitute, thereby reducing plastic waste and exposure to leaking bottles.

- Reduce: In order to reduce plastic pollution, there is need to reduce our usage of plastic. This translates to changing our daily attitudes and avoiding the use of plastic when there is a better alternative to it and only using plastic when it is seriously needed. Plastic packaging need to be avoided. Today, shops are seen offering products such as cereals, nuts, beans and pasta without packaging. Instead, reusable bags or jars are used.

- Recycle: Recycling of plastic involves collection of plastic waste and reprocessing it into new products, in order to reduce the amount of plastic in the waste stream. It is known that plastic does not break down easily, so to recycle plastic mean it is still plastic, but it can be used for another purpose entirely. Recycling does not cut down on plastic, it is still the existing plastic that are used for recycling processes but are transformed to a new one. Therefore, recycling process does not mean that the amount of plastic or exposure is being reduced. Plastic is a useful material, but it is very important that plastic waste is properly recycled and does not end up in the environment. A great job needs to be done on recycling because findings show that less than 14 percent of plastic packaging is recycled. So people need to avoid plastic packing and do not buy water in plastic bottles.

- Educate Businesses: Education is an important solution in order to increase awareness and behavioural/attitudinal change. People need to be guided and advised on plastic disposal so as to prevent the occurrence of plastic pollution. There is need to speak to operators/owners of local restaurants and businesses about that the alternatives that they can divert to for stokinr, packaging items. Many companies are springing up with excellent low-cost replacements, such as bamboo utensils in place of plastic ones. The operators of restaurants, events centres, and businesses need to be guided to refuse straws when requested by their customers to drink beverages, beers and soft drinks such as Cocacola etc. They should not allow their customers to use any plastic drinking straws. Rather, they can use glasses at the bar; restaurant or events centres and bring their own drinking straws made of glass, steel or bamboo.

According to [5], National Environmental Standard, and Regulation Enforcement Agent, (NESRER A) has aligned with the Food Beverage Recycling Alliance (FBRA) and other manufacturers to fight the plastic menace. Pioneer members of the alliance are Coca-cola Nigeria Ltd., Nigerian Bottling Company Ltd (NBC), Nigerian Breweries PLC, Seven-up Bottling Company Limited and Nestle Nigeria Limited. FBRA is a global framework of action for a collaborative and partnership approach between government, business and the larger society towards achieving a zero-waste society. The alliance is committed to ensuring through its educative and communication change awareness programmes, proper waste disposal, collection and recycling of packaging waste. the chairperson of the alliance, Mrs. Sade Morgan told the guardian that FBRA is an industry driven producers' Responsibility Organization that is committed to achieving a cost-effective and efficient post-consumer polyethylene terephthalate (PET) bottles collection scheme through recognise collectors and recyclers in Nigeria. She explained that the alliance has structured its implementation programmes into three categories. First: Communication and 


\section{International Journal of Engineering Applied Sciences and Technology, 2020 \\ Vol. 4, Issue 12, ISSN No. 2455-2143, Pages 85-95 \\ Published Online April 2020 in IJEAST (http://www.ijeast.com)}

advocacy intervention to educate the populace on proper waste disposal of PET. Second: Collection of post-consumer waste PET from the environment through designated collectors and placement of bins in strategic locations. Third: Partnership with recyclers or off - takers to convert the collected PET to other uses like energy, fiber and textiles.

- Government Intervention: The lawmakers and government need to arise and get involved in the prevention of plastic pollution so as to create fear in public and allow strict adherence to preventive measures to take place. Presently, awareness and sensitization is on-going all over the globe on plastic pollution. Various governments are planning different measures to reduce the volume of plastic waste. For instance, the Government of Belgium has concluded and agreed with Detic, which is an association for producers and distributors of cosmetics, cleaning and maintenance products, adhesives and sealants. Here, the Government focuses on how to fully replace plastic microbeads in cosmetics and rinse-off products for oral care by the end of the year 2019.

Based on the United Nation (UN) conference on oceans in the year 2019, the member states made agreement to reduce the use of plastics and microplastics in the long term. The European Union (EU) has planned to restrict the one-off use of plastic and during the World Environment Day in the year 2018, plastic waste was put in the spotlight by the UN to be discussed and deliberated upon.

According to [6], the ban on nonbiodegradable plastic shopping bags has taken a heavy toll on the subsistence economy of Cameroon. Sellers and consumers of nonbiodegradable plastic shopping bags are expected to comply with the new regulation prohibiting/stopping the use of nonbiodegradable plastic shopping bags and encouraging the use of thicker, more durable recyclable bags.

According to [5], Mrs. Shade Morgan said that FBRA and Lagos State Government will jointly found public awareness campaigns and advocacy on appropriate packaging waste disposal systems. Besides this, the alliance has a plan of activities, which includes collection of PET in partnership with identified collectors to retrieve and clear PET from streets, landfills and waterways. The alliance is fully committed to driving through its educative and communication change awareness programmes that there is proper waste disposal. This would culminate in developing effective collection systems and then recycling of packaging wastes. This must be in partnership with federal and state governments, regulatory agencies, private collectors, recyclers and other relevant stakeholders as added by Morgan.

The Nigerian Bottling Company Ltd (NBC) which is one of the leading manufacturers of plastic bottled products, revealed that the country has a Post-Consumer Packaging Waste Management Policy Statement, which support the collection and recycling of all packaging wastes, including PET and guide its activities. NBC is taking measures to engage in public awareness campaigns, selective waste collection education and anti-littering campaigns. Littering of our environment is the major culprit in environmental pollution and once this is addressed; our streets, drainages and waterways will be free from plastic [5].

- Use of Oxo-Biodegradable Additive: Scientists are making collaborative efforts around the world to find lasting and contributory solution to the negative impact of plastics materials (which cause litter, choking of drainage system and marine life) on the environment through on-going research.

According to [10], a lot of technologies are being developed for recycling of plastics while other efforts are being made on other areas including how to make plastics to be biodegradable. The contributory solution, based on the recent discovery, using just $1 \%$ Oxobiodegradable (OBD) additive in the manufacture of plastics materials. This additive (OBD) is said to make any various plastic materials biodegrade after a short period of time. A number of countries in Europe, Latin America, South Asia, Middle East and Africa are already using OBD in tackling the menace of plastics that have escaped collection and therefore pollutions the environment. The need for Oxobiodegradable (OBD) plastics is indeed obvious. Thousands of tons of plastic waste is escaping collection, getting into the world's environment every day, and unless treated with just a $1 \%$ inclusion of Oxo- biodegradable additive will remain there for decades. Oxo-biodegradable plastics have been independently tested and found ultimately biodegradable on land or in the sea. The best and most pragmatic option remains to increase the infrastructure for the collection 


\section{International Journal of Engineering Applied Sciences and Technology, 2020 \\ Vol. 4, Issue 12, ISSN No. 2455-2143, Pages 85-95 \\ Published Online April 2020 in IJEAST (http://www.ijeast.com)}

and recycling of plastics and at the same time make it mandatory for the use of Oxobiodegradable additives, which will then help to mitigate the menace of plastic waste that escapes collection and ends up polluting the country.

\section{FINDING AND SUGGESTIONS}

- Plastic bags and garbage that are thrown into the ocean have devastating effect on sea animals.

- Over $60 \%$ of the trash that ends in dustbin could be recycled.

- Plastic bags that are thrown into the ocean kill over a million sea creatures a year.

- Plastic pollution threatens food safety and quality, human health, coastal tourism, and contributes to climate change.

- Americans normally use over two and a half million plastic bottles every thirty minutes, and most of them are simply thrown away rather than recycled.

- Findings show that bodies of $90 \%$ of Seabirds contain plastic debris.

- Plastics contribute to approximately $10 \%$ of discarded waste

- Research suggested that by 2050 , there could be more plastic than fish in the oceans by weight.

- Findings show that there are ten (10) largest emitters of oceanic plastic pollution worldwide which are from the most to the least: China, Indonesia, Philippines, Vietnam, Sri Lanka, Thailand, Egypt, Malaysia, Nigeria, and Bangladesh.

\section{CONCLUSION}

Plastic is non-biodegradable. It is nearly impossible for it to break down. It sticks around for a long number of years longer (e.g up to 1,000 years longer) than other forms of trash. Plastic is basically everywhere. Negligence is the main cause of plastic pollution. The estimation shows that $80 \%$ of marine litter emanates/originate from land. This plastic pollution comes mainly from household waste, which is poorly recycled, dumped in landfills or abandoned in nature. These wastes are carried by the winds, pushed by the rains into sewers, streams, rivers, and finally in the oceans. Natural disasters such as floods must be put into consideration as other causes of pollution as well.
Humans drinks a lot of water everyday so as to keep the body system hydrated throughout the day. This is mainly achieved by taking plastic water bottles, due to its portability. Most of these are only recommended for single use, signifying that whenever a bottle is finished by someone, it goes into the trash. Also, it is unfortunate today that commuters and motorists plying our highways have littered our roads with plastic bottled water and soft drinks. Plastic bottles are found at the both sides of the road being discarded recklessly by the commuters after being used neglecting the consequence. So there is need to get rid of this menace.

The resin based plastic producers need to change their practices and mode of operations. This is because the consumers do not want the world to be destroyed by plastic waste. So there is need to switch to recycled plastics.

People are enjoined/advised to avoid bring plastic bags to their various homes and purchasing items with too much packaging. This way you can help in contributing towards the environment in the form of reducing plastic pollution whose ill effects are not reversible. Plastic bags can be replaced by reusable bags. This paper urges everyone to shift to using recycled plastic, and contribute to a fund to help clean up our world.

\section{REFERENCES}

1. https://en.m.Wikipedia.org/wiki/plastic pollution Accessed $4^{\text {th }}$ November, 2019.

2. Starr, C. and McMillan, B. (2007). Human Biology, Seventh Edition, Thomson Brooks/Cole, Belmont, California, pp.464,466,481-482

3. Fellman, J.D.; BJelland, M.D.; Montello, D.R.; Gettis, A. and Gettis, J. (2013). Human Geography: Landscapes of Human Activities, Twelfth Edition, McGraw-Hill Companies, New York, pp.431.

4. Miller Tyler, JR. G. and Spoolman, S.E. (2010). Environmental Science, Thirteenth Edition, International Edition, Brook/Cole, Belmont, California, pp.370, 412.

5. Uwaegbulam, C.; Nwannekanma, B. and Gbonegun, V. (2018). Producers' Responsibility and Plastic Pollution Crisis, The Guardian Newspaper, (Vol. 35 No. 14350, pp.32-33).

6. Njomo, L.M (2019). The Ban on Plastic Shopping Bags in Cameroon: An Exploratory Study of Resilience Strategies 
of Subsistence Marketplaces. International Journal of Innovative Science and Research Technology. (Vol. 4 No. 4, pp. 475-493).

7. McConnel, D.; Steer D.; Knight, C. and Owens, B. (2010). The Good Earth: Introduction to Earth Science, Second Edition, McGraw-Hill Companies, New York, pp. 316.

8. Plummer, C.C.; Carlson, D.H. and Hammersley, L. (2010). Physical Geology, Thirteenth Edition, McGraw-Hill Companies, New York, pp.292.

9. Fellman, J.D.; Gettis, A.; Gettis, J. and Malinowski, J.C. (2005). Human Geography: Landscapes of Human Activities, Eight Edition, McGraw-Hill Companies, New York, pp.509-510.

10. Phillips, A. (2019). Plastics and use of Oxobiodegradable, The Guardian Newspaper, (Vol.48 No. 56, pp.44). 